\title{
The Dental Caries Pandemic and Disparities Problem
}

\section{BL Edelstein*}

Address: Section of Social and Behavioral Sciences, College of Dental Medicine, Columbia University, New York, NY, USA; Childrens Dental Health Project, Washington DC, USA

Email: BL Edelstein* - ble22@columbia.edu

* Corresponding author

from Biotechnology and Biomaterials to Reduce the Caries Epidemic

Seattle, USA. 13-15 June 2005

Published: 10 July 2006

BMC Oral Health 2006, 6(SuppI I):S2 doi:I0.1 186/1472-683I-6-SI-S2

(C) 2006 Edelstein; licensee BioMed Central Ltd.

This is an open access article distributed under the terms of the Creative Commons Attribution License (http://creativecommons.org/licenses/by/2.0), which permits unrestricted use, distribution, and reproduction in any medium, provided the original work is properly cited.

\begin{abstract}
Understanding caries etiology and distribution is central to understanding potential opportunities for and likely impact of new biotechnologies and biomaterials to reduce the caries burden worldwide. This review asserts the appropriateness of characterizing caries as a "pandemic" and considers static and temporal trend reports of worldwide caries distribution. Oral health disparities within and between countries are related to sugar consumption, fluoride usage, dental care, and social determinants of health. Findings of international and U.S. studies are considered in promoting World Health Organization's and others' recommendations for science-based preventive and disease management interventions at the individual, clinical, public health, and public policy levels.
\end{abstract}

\section{Introduction \\ "Pandemic"}

Understanding caries etiology and distribution is central to understanding the potential opportunities for and likely impact of new biotechnologies and biomaterials to reduce the caries burden worldwide [1]. The term pandemic is customarily reserved for global disease outbreaks that are acute and fatal, such as the influenza epidemic of 1918 that killed tens of millions globally. In contrast to the term epidemic, from the Greek language roots for "upon" and "the people," pandemic refers to a disease that is visited upon "all the people." It suggests an impact on populations of entire countries, continents, or much of the world. The term therefore implies two elements: global distribution and severe consequence. By characterizing dental caries as a pandemic, symposium organizers have focused attention on caries as a highly prevalent disease around the globe. They have also implied that it has profound individual and societal significance because of its often severe, though non-fatal, consequences.

Caries is both diet-dependent and fluoride-mediated and is amenable to prevention and management at both the individual and population levels. It is also readily treatable through conventional surgical interventions and dental repair. Therefore, the extent and severity of its consequence for individuals, communities, and nations varies by the availability and balance of these factors. As a result, there are marked disparities in caries experience, treatment experience, and disease consequences both between countries and within countries. The term pandemic is fitting because those who are affected by caries and have little or no access to care number in the hundreds of millions, reside on all continents and in most societies, and experience significant consequences of pain and dysfunction that impair their most basic functions of 


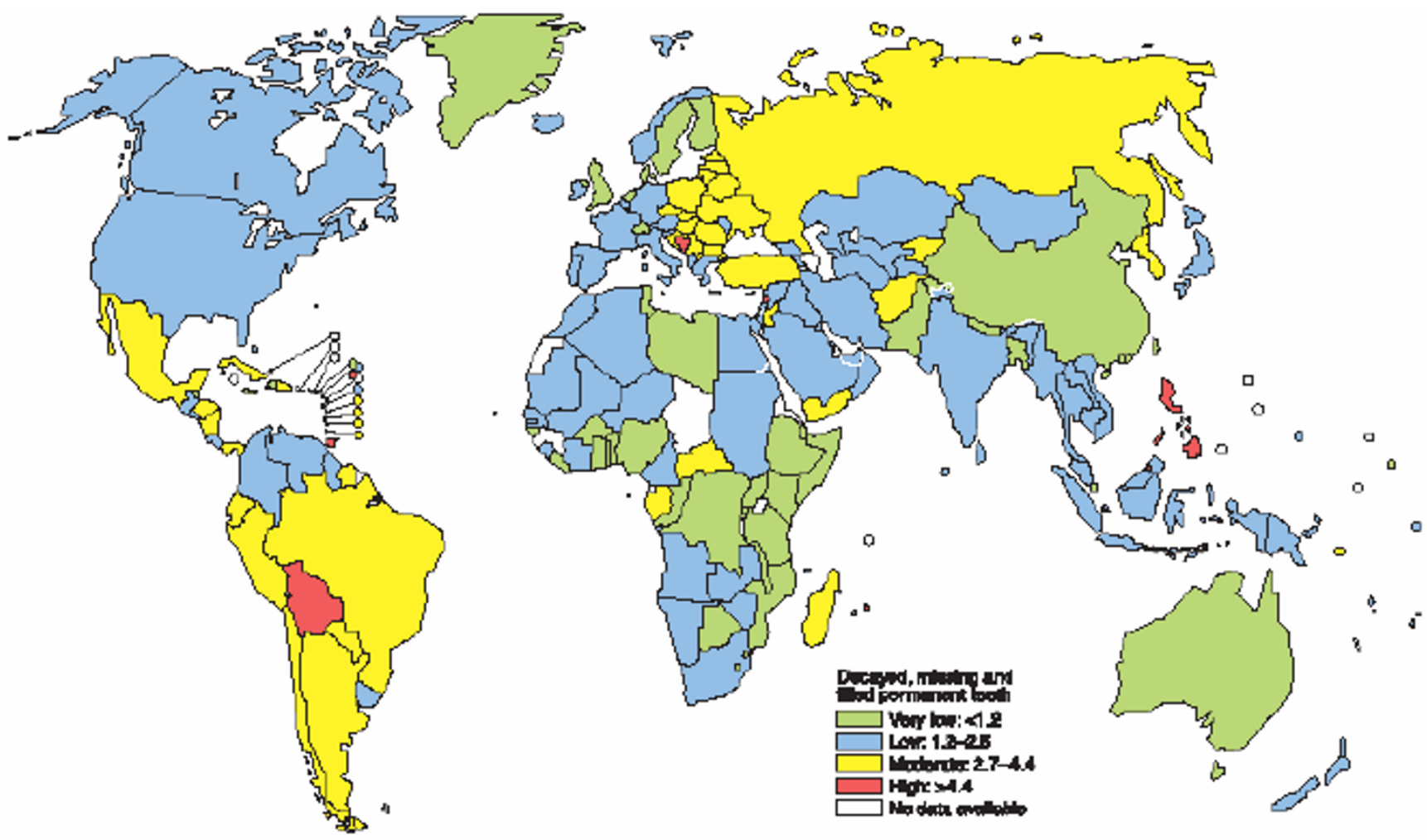

\section{Figure I}

Dental caries levels (DMFT) of I2-year-olds worldwide. World Health Organization [2].

eating, sleeping, speaking, being productive and enjoying general health as defined by the World Health Organisation.

\section{Static View of Caries Distribution}

The World Health Organization's 2003 report on oral health [2] provides an overview of global caries epidemiology that confirms its international pandemic distribution. Globally, WHO reports caries prevalence in schoolage children at $60-90 \%$ and as virtually universal among adults in the majority of countries [3]. Because so few countries are spared high levels of this disease, caries maps typically display disease severity rather than prevalence. Figure 1 displays caries distribution among 12 year olds by average numbers of teeth affected, using the Decayed, Missing, and Filled Teeth (DMFT) index of severity. The map shows a clear pattern of higher disease experience in North and South America, Western Europe, and much of Africa; more moderate disease experience in much of South America, Russia, and the former Soviet Republics; and low levels of disease in Eastern Africa, China, Australia, and Greenland. While the correlation between caries rates and national development is not tight, WHO has observed that developed countries have higher rates of caries experience, while developing countries have lower rates [2]. WHO has attributed these differences to the rel- ative availability of simple sugars in diets, to fluoride, and to dental treatment. U.S. findings by the Centers for Disease Control and Prevention (CDC) [4] released in August 2005 reveal high ongoing prevalence of dental caries in children, with $27 \%$ of preschoolers, $42 \%$ of school-age children, and $91 \%$ of dentate adults having caries experience. Paralleling international findings of country $[5,6]$ and family level $[7,8]$ income-related disparities (dubbed "dental caries polarization") [9], the new U.S. report reveals ongoing [10] marked disparities by income. For example, primary tooth caries prevalence is 1.8 times greater for children of poverty than for those with incomes twice the poverty level.

\section{Dynamic View of Caries Distribution}

Konig [11] notes that the "[caries] situation worldwide was and remains today extremely variable and changes are occurring in different directions." Commenting on these variances, Petersen et al. [3] note that the "current pattern of oral disease reflects distinct risk profiles across countries related to living conditions, lifestyles and environmental factors, and the implementation of preventive oral health schemes." These factors typically relate to differences in disease experience across countries but also reflect social gradients within countries. The study of social determinants of health when applied to oral health 
suggest that stages of societal development as well as individual circumstances play critical roles in caries acquisition and expression.

International correlates of pediatric caries experience have been explored in a search for appropriate nation-level preventive policies and programs. Comparing disease rates in 109 countries, higher levels of childhood caries were found to correlate with total sugar consumption, urbanization, and level of development but not with gross domestic product, total healthcare spending, or dentistto-population ratio [12]. The quality of care provided to individuals suffering the affects of dental caries, however, does vary by provider availability as extraction is more common than dental repair in countries with fewer dentists [3].

Longitudinal global trends described in the WHO report [2] demonstrate the "tyranny of the mean" when considering the dynamism of caries' distribution in populations. Average caries rates worldwide among 12-year-olds expressed as DMFT have remained reasonably steady, around 2.5, since 1980. However, trend lines for developed and developing countries are diametrically different. Developed countries have experienced almost linear decreases in caries rates among the benchmark 12-yearolds from >4.5 DMFT in 1980 toward the mean, while developing countries have experienced ongoing increments also approximating the mean.

While caries is declining in some countries and increasing in others, once established in a population, it does not decline to pre- sugar availability baseline levels except under extraordinary circumstances of deprivation, $[13,14]$. As sugar accounts for the majority of variance in caries rates among countries [15] and continues to be readily available once introduced, the majority of polled international cariology experts concur that changes in sugar consumption contribute considerably less to caries declines relative to the contribution of fluorides [16].

CDC's cross-sectional trend analysis over a recent decade [4] parallels WHO's findings for developed countries, with caries declining significantly $(7.4 \%)$ in permanent teeth of school-age children and adolescents. However, a trend toward increased primary tooth caries and a growing subpopulation of Latino children with higher caries rates suggests that the next cohort of U.S. children may demonstrate a reversal in caries declines.

\section{Disparities and Social Determinants of Dental Caries}

Increasing attention is being paid to differences in population subgroups in characterizing the distribution and correlates of dental disease, particularly in children [1720]. Petersen and Lennon [21] summarize these differ- ences, stating that "Despite great improvements in the oral health of populations across the world, problems still persist particularly among poor and disadvantaged groups in both developed and developing countries." Even within a single country, disparities by social standing exist in large part because of differences in diet, fluoride use, and social empowerment. Disparities by social empowerment persist both because of lack of access to dental care [22] and despite such access [23], since differences in care utilization vary even when care is available.

Theoretical frameworks that explicate pathways between social, behavioral, and political factors and health [24] are being applied to oral conditions [25] to identify relationships that may be actionable. These factors have been identified as strong correlates, if not determinants, of oral health in populations and sub-populations [26] and have been considered as potentially fruitful factors for intervention to improve both oral and general health. WHO's recently formed Commission on Social Determinants of Health, like national health plans in England, Canada, and Sweden seek political interventions that hold promise to improve health by addressing such social determinants.

Concise messages to public policymakers regarding caries interventions have been developed by a number of organizations to promote public adoption of science- and technology-based interventions that hold strong promise to reduce the caries pandemic. For example, the Washington DC-based Children's Dental Health Project (http:// www.cdhp.org, accessed September 5, 2005) states "Too many children suffer too much from a disease that is well understood and almost completely preventable. Childhood tooth decay is the rare example of a very common and consequential health problem that can be solved through public interventions without incurring extreme costs."

\section{Implications of Caries Epidemiology for Research, Clinical Practice, and Public Policy}

"One-size-fits-all" approaches to prevention and disease management of individuals and groups fail profoundly to reflect important differences in disease experience within and between populations. Needed today are bio-technologic/bio-material, clinical, behavioral, and social interventions that are risk-based, subpopulation-targeted, agespecific, biologically sound, and safe and accepted at both individual and population levels. Typical approaches to dental care - whether limited to extractions or involving complex dental restorations - often fail to capitalize on current scientific understanding of disease distribution, correlates, and pathogenesis. By not thinking about, managing, and treating dental caries as the dynamic, progressive, infectious, diet-dependent, behavioral disease that it is, clinicians and program managers miss opportunities to 
bring the power of sound science to bear on a disease that remains prevalent and consequential to the daily lives of millions of children worldwide. This is due in part to the failure of technology- and knowledge-transfer from the cariology laboratory to the dental chair and family home so that providers and individuals can successfully shift their orientation from treating signs and symptoms of caries to managing the underlying disease process. Although caries is a disease that manifests throughout the lifespan, prioritizing children is appropriate because caries is first established in early childhood and plays out across the lifetime. Current conceptual frameworks that need to be addressed include shifting from characterizing dental caries as a condition to a disease; from passive to active management; from static to dynamic understanding of pathogenesis; from treatment to management; and from dento-centricity to individual and family centricity.

WHO recommends oral health interventions that (1) reduce disease burden through a "risk-factor" approach that focuses on high needs individuals and groups; (2) promote healthy lifestyles and reduce risk factors arising from environmental, economic, social, and behavioral sources; (3) develop oral health systems that equitably improve oral health outcomes, respond to legitimate needs, and are financially fair, and (4) integrate oral health into national and community health programs and promote oral health in public policy. The 2001 U.S. Surgeon General's invitational Workshop on Children and Oral Health focused attention on public and private policy interventions suitable for young children, including (1) start early and involve all who come in contact with young children and their families; (2) assure competencies of all providers; (3) be accountable through tracking and performance measures; (4) take public action through coalitions; (5) maximize utility of sound science; (6) improve public programs for the underserved; (7) grow an adequate and competent dental workforce; and (8) empower families to address their oral health [27].

\section{Conclusion}

Noting the wide variation among countries in physical and economic resources available for dental care, WHO's Poul Erik [3] calls for prioritizing cost-effective preventive interventions over curative care. The biotechnological and biomaterials approaches to caries prevention and management proposed by this NIDCR funded Symposium (Biotech and Biomaterials Research to Reduce the Caries Epidemic) represent an essential and timely response to that call.

\section{Competing interests}

The author(s) declare that they have no competing interests.

\section{Acknowledgements}

This report was supported by the sponsors of the University of Washington Conference on Biotech and Biomaterials Research to Reduce the Caries Epidemic, June 13-15, 2005. Seattle, WA.

\section{References}

I. Holst D: Causes and prevention of dental caries: a perspective on cases and incidence. Oral Health Prev Dent 2005, 3:9-14.

2. Petersen PE: The World Oral Health Report. Geneva, Switzerland: World Health Organization; 2003.

3. Petersen PE, Bourgeois D, Ogawa H, Estupinan-Day S, Ndiaye C: The global burden of oral disease and risks to oral health. Bulletin of the World Health Organization 2005, 3:66I-669.

4. Beltran-Aguilar ED, Barker LK, Canto MT, Dye BA, Gooch BF, Griffin SO, et al.: Surveillance for dental caries, dental sealants, tooth retention, edentulism, and enamel fluorosis - United States, 1988-1994 and 1999-2002. In MMWR CDC Surveill Volume 54. Atlanta, GA: US Department of Health and Human Services, Centers for Disease Control and Prevention; 2005: I-44.

5. Pine CM, Adair PM, Nicoll AD, Burnside G, Petersen PE, Beighton D, et al: International comparisons of health inequalities in childhood dental caries. Community Dent Health 2004, 2I(suppl): I2I-I30.

6. Robert $Y$, Sheiham $A$ : The burden of restorative dental treatment for children in Third World countries. Int Dent J 2002, 52:I-9.

7. Downer MC, Drugan CS, Blinkhom AS: Dental caries experience of British children in an international context. Community Dent Oral Epidemiol 2005, 22:86-93.

8. Brennan D, Spencer AJ: Changes in caries experience among Australian public dental patients between $1995 / 96$ and $200 \mathrm{II}$ 02. Aust N ZJ Public Health 2004, 28:542-548.

9. daSliva Bastos R, Olympio KP, Bijella VT, Buzalaf MA, deMagalhaes Bastos JR: Trends in dental caries prevalence in I2-year-old schoolchildren between 1976 and 2001 in Bauru, Brazil. Public Health 2005, I | 9:269-275.

10. Vargas CM, Crall JJ, Schneider DA: Sociodemographic distribution of pediatric dental caries. NHANES III, 1988-1994. 1998, 129:1229-1238.

II. Konig KG: Clinical manifestations and treatment of caries from 1953 to global changes in the $20^{\text {th }}$ century. Caries Res 2004, 38: 168-172.

12. Diehnelt $D E$, Kiyak HA: Socioeconomic factors that affect international caries levels. Community Dent Oral Epidemiol 200I, 29:226-233.

13. Toverud G: The influence of war and post-war conditions on the teeth of Norwegian school children. III. Discussion of food supply and dental condition in Norway and other European countries. Milbank Mem Fund Q 1957, 35:373-459.

14. Takeuchi M: Epidemiological study on dental caries in Japanese children before, during and after WWII. Int Dent J I96I, I I:443-457.

15. Moynihan PJ: The role of diet and nutrition in the etiology and prevention of oral diseases. Bulletin of the World Health Organization 2005, 83:694-699.

16. Bratthall D, Hansel-Petersson G, Sunberg H: Reasons for the caries decline: what do the experts believe? Eur J Oral Sci 1996, 104:416-432.

17. Willems S, Vanobbergen J, Martens L, DeMaeseneer J: The independent impact of household- and neighborhood-based social determinants of early childhood caries: a cross sectional study of inner-city children. Fam Community Health 2005, 28:168-175.

18. Hallett KB, O'Rourke PK: Social and behavioural determinants of early childhood caries. Aust Dent J 2003, 48:27-33.

19. Reisine ST, Psoter W: Socioeconomic status and selected behavioral determinants as risk factors for dental caries. J Dent Educ 200I, 65:1009-1016.

20. Pattussi MP, Marcenes W, Croucher R, Sheiham A: Social deprivation, income inequality, social cohesion and dental caries in Brazilian school children. Soc Sci Med 200I, 53:915-925.

21. Petersen PE, Lennon MA: Effective use of fluorides for the prevention of dental caries in the $2^{\text {st }}$ century: the WHO approach. Community Dent Oral Epidemiol 2004, 32:319-321. 
22. US Department of Health and Human Services: Oral Health in America: A Report of the US Surgeon General. Rockville, MD: US Department of Health and Human Services, National Institute of Dental and Craniofacial Research, National Institutes of Health; 2000.

23. Ismail Al, Sohn $\mathrm{W}$ : The impact of universal access to dental care on disparities in caries experience in children. J Am Dent Assoc 200I, 132:295-303.

24. Marmot M: Social determinants of health inequalities. Lancet 2005, 365: 1099-1104.

25. Newton JT, Bower EJ: The social determinants of oral health: new approaches to conceptualizing and researching complex causal networks. Community Dent Oral Epidemiol 2005, 33:25-34.

26. Sheiham A, Watt RG: The common risk factor approach: a rational basis for promoting oral health. Community Dent Oral Epidemiol 2000, 28:399-406.

27. Edelstein BL: Forward to the US Surgeon General's Workshop on Children and Oral Health. Ambulat Pediatr 2002, 2:SI39-I40.

Publish with Biomed Central and every scientist can read your work free of charge

"BioMed Central will be the most significant development for disseminating the results of biomedical research in our lifetime. "

Sir Paul Nurse, Cancer Research UK

Your research papers will be:

- available free of charge to the entire biomedical community

- peer reviewed and published immediately upon acceptance

- cited in PubMed and archived on PubMed Central

- yours - you keep the copyright

Submit your manuscript here:

http://www.biomedcentral.com/info/publishing_adv.asp 